\title{
Preparation of oil palm empty fruit bunch based activated carbon for adsorption of dye from aqueous solution
}

\author{
Narisara Intarachandra ${ }^{1, *}$, Sukum Siriworakon ${ }^{1}$, and Theerapol Sangmanee ${ }^{1}$ \\ ${ }^{1}$ Department of Chemical Engineering, Mahanakorn University of Technology,Bangkok 10530, Thailand
}

\begin{abstract}
The objectives of this research are to determine an optimum condition for producing the activated carbon from oil palm empty fruit bunch (OPEFB) and used as an adsorbent to remove methylene blue (MB) dye from aqueous solution. Chemical activation by phosphoric acid $\left(\mathrm{H}_{3} \mathrm{PO}_{4}\right)$ was used as a procedure to modify OPEFB, in which in this study the carbonization and activation were done simultaneously. The concentrations of phosphoric acid were varied from 20-60\% by weight and carbonization temperature and time were varied from $500-800^{\circ} \mathrm{C}$ and $30-60$ minutes, respectively. It was found that among the conditions used, the best condition for producing activated carbon was obtained when using $60 \% \mathrm{H}_{3} \mathrm{PO}_{4}$ and carbonized at $500^{\circ} \mathrm{C}$ for 30 minute. The produced activated carbon had a surface area of $362.5 \mathrm{~m}^{2} / \mathrm{g}$ and average pore size of $2.94 \mathrm{~nm}$. Methylene blue and Iodine numbers were 13.62 and 356.46 $\mathrm{mg} / \mathrm{g}$, respectively, which were comparable to the results of commercial activated carbon; i.e. 6.96 and $778.7 \mathrm{mg} / \mathrm{g}$. The optimum condition for the adsorption of MB from synthetic wastewater by produced activated carbon was found at $\mathrm{pH} 8-12$ with equilibrium time of 4 hours. Results demonstrated that the equilibrium data was well fitted by Freundlich isotherm model with the isotherm constants $\mathrm{K}_{\mathrm{F}}$ of $7.75 \mathrm{mg} / \mathrm{g}$ and $1 / \mathrm{n}$ of 0.13 .
\end{abstract}

\section{Introduction}

Wastewater from tanning industry is one of the important environmental problems in Thailand. It has a wide impact especially on the communities around the plant. Reducing the toxicity of wastewater before releasing to the environment is a way to reduce the conflict between the factory and the surrounding community, and also compliance with an environmental legal standard.

Basic Dye is one of major dyes normally used in tanning industry. The dye molecule is composed of cationic ions and sometimes referred to as cationic dye. Methylene blue is an example of basic dye. Recently, there are many methods to remove dyes from wastewater such as; chemical precipitation, reverse osmosis, adsorption process, etc. Among these, adsorption by activated carbon is one of the promising processes since it is cheap, easy to operate and no chemical additional.

Oil Palm Empty Fruit Bunch (OPEFB) is waste material generated from crude palm oil extraction industry. Although, it is normally used as biomass fuel in a furnace to produce steam for palm oil production process, but many tons were generated each year and thus need to be removed. OPEFB is composed mostly of cellulose, hemicellulose and lignin with high fiber contents and large fiber size, so it has the ability to be used as a substrate for producing activated carbon [1-3].
Thus, the aim of this study was to investigate the removal of methylene blue by adsorption process using activated carbon prepared from OPEFB. 2-Level Full factorial design experiments were carried out; parameters such as concentration of activation reagent, temperature and carbonation time were varied to investigate their effect on activated carbon performance and theirs use for Methylene blue adsorption.

\section{Materials and methods}

\subsection{Materials and reagents}

OPEFB was obtained from Thai Taro \& Oil Company, Ltd., the palm oil production company located at Surat Thani province in the South of Thailand. OPEFB was first washed, cut into 2-3 cm length size and then dried in an oven at $105^{\circ} \mathrm{C}$ for $12 \mathrm{~h}$ before use. Phosphoric acid $>85 \%$ and Methylene blue used in this study were analytical grade obtained from Ajax Finechem and Merck, respectively. Nitrogen gas was from Airgas and used in high purity $(>99.999 \%)$.

\subsection{Synthesis of activated carbons from OPEFB}

Dried OPEFB was chemical and physical activated by adding into $500 \mathrm{~mL}$ beaker containing a desired

\footnotetext{
*Corresponding author: narisara@ mutacth.com
} 
concentration phosphoric acid solution. The beaker was then placed on a heater stirrer and heated the mixture at $70^{\circ} \mathrm{C}$ for $1 \mathrm{~h}$ before left at room temperature for $2 \mathrm{~h}$ to cool down. Activated OPEFB was washed with distilled water 3-4 times until $\mathrm{pH} 7$ was achieved, after that dried in an oven at $105^{\circ} \mathrm{C}$ for $12 \mathrm{~h}$. The chemical and physical activated OPEFB was carbonized at different temperatures, under nitrogen atmosphere for different activation time. Nitrogen flow rate at $0.50 \mathrm{~L} / \mathrm{min}$ and the rate of increasing temperature at $10^{\circ} \mathrm{C} / \mathrm{min}$ were controlled during the carbonization. OPEFB based activated carbon was then weighed, ground and sieved to size $<150$ microns, and kept in a desiccator before used.

In order to find the key variables affecting \% yield and the adsorption capacity of activated carbon, the twolevel full factorial design experiments were carried out and the conditions used are shown in Table 1. Different parameters including acid concentration $(20 \%$ :low and $60 \%$ :high), temperatures $\left(500{ }^{\circ} \mathrm{C}\right.$ :low) and $800^{\circ} \mathrm{C}$ :high), and activation times (30min:low and 60min:high) were selected to evaluate the performance of activated carbon produced. The total number of the experiments was 9 including one central point (average of high and low values for each parameter).

Table 1. 2-Level Full Factorial Design Experiments

\begin{tabular}{|c|c|c|c|}
\hline RUN & $\begin{array}{c}\text { Phosphoric acid } \\
\text { Concentration } \\
\text { )weight } \%(\end{array}$ & $\begin{array}{c}\text { Calcination } \\
\text { Temperature } \\
\left({ }^{\circ} \mathbf{C}\right)\end{array}$ & $\begin{array}{c}\text { Time } \\
(\mathbf{m i n})\end{array}$ \\
\hline AC1 & 20 & 500 & 30 \\
\hline AC2 & 20 & 500 & 60 \\
\hline AC3 & 60 & 500 & 30 \\
\hline AC4 & 60 & 500 & 60 \\
\hline AC5 & 20 & 800 & 30 \\
\hline AC6 & 20 & 800 & 60 \\
\hline AC7 & 60 & 800 & 30 \\
\hline AC8 & 60 & 800 & 60 \\
\hline AC9 & 40 & 650 & 45 \\
\hline
\end{tabular}

\subsection{Methylene blue (MB) adsorption only}

The applicability of OFEFB based activated carbon to remove Methylene blue dye was performed by adding $0.5 \mathrm{~g}$ adsorbent in a $250 \mathrm{~mL}$ conical flask containing 50 $\mathrm{ml}$ of dye solution concentration ranging from 20 to 250 $\mathrm{mg} / \mathrm{L}$ at ambient temperature $\left(28 \pm 2^{\circ} \mathrm{C}\right)$. The effect of solution $\mathrm{pH}$ was studied in the range of 2-12. The $\mathrm{pH}$ of the solution was adjusted by using $\mathrm{HCl}$ or $\mathrm{NaOH}$. Effects of initial MB concentration (20-100 mg/L), adsorbent dosage $(0.1-1.0 \mathrm{~g} / 50 \mathrm{~mL}$ solution) were also investigated. All experiments were performed at $120 \mathrm{rpm}$ stirring speed and done 3 times replicate to find average value. After fixed time, the sample was collected, filtered, and the concentration of dye remain in supernatant solution was determined using UV-VIS spectrometer at 663 nanometer wavelength. The adsorption capacity $(\mathrm{mg} / \mathrm{g})$ of OPEFB based activated carbon for Methylene blue was calculated from:

$$
q_{t}=\frac{\left(C_{o}-C_{f}\right) V}{m}
$$

where $\mathrm{q}_{\mathrm{t}}$ is the adsorption capacity $(\mathrm{mg} / \mathrm{g})$ at time $t, \mathrm{C}_{\mathrm{o}}$ and $\mathrm{C}_{\mathrm{f}}$ are the initial and final concentration $(\mathrm{mg} / \mathrm{L})$ of $\mathrm{MB}$, respectively. $\mathrm{V}$ is the volume (L) of dye solution and $\mathrm{m}$ is the weight $(\mathrm{g})$ of activated carbon.

\subsection{Characterization techniques and measurement}

Proximate analysis was done on raw OPEFB to calculate amount of water (moisture), ash, volatile matter, and fixed carbon contents by following ASTM standard procedures (ASTM D3173-87, D3174-93, and D317589) and the result is shown in Table 2. Low amount of ash and high content of fixed carbon indicated that OPEFB was suitable as a raw material for synthesizing activated carbon.

Table 2 Proximate analysis of raw OPEFB

\begin{tabular}{|l|l|l|l|l|}
\hline & $\begin{array}{l}\text { Water } \\
\text { (moisture) }\end{array}$ & ash & VM & FC \\
\hline Raw OPEFB & $17.81 \%$ & $5.31 \%$ & $54.47 \%$ & $22.41 \%$ \\
\hline
\end{tabular}

A BET surface area analyzer was used to measure nitrogen adsorption isotherm at $77 \mathrm{~K}$, specific surface area, total pore volume, and average pore size of the activated carbon were obtained from the adsorption isotherm. The surface morphology of activated carbon was observed by Scanning Electron Microscope (SEM). Standard testing method JIS K 1470-1991 and ASTM D4607 were used to determine Methylene Blue Number and Iodine Number of the activated carbon. The point of zero charge (PZC) of the activated carbon used for adsorption experiment was determined, for this, $0.5 \mathrm{~g}$ of activated carbon was added to $100 \mathrm{ml}$ of deionized water with varying $\mathrm{pH}$ from 2 to 12 (adjusted by $0.1 \mathrm{M} \mathrm{HCl}$ or $\mathrm{NaOH}$ solution) and stirred at $120 \mathrm{rpm}$ for $24 \mathrm{~h}$. Difference between final $\mathrm{pH}$ and initial $\mathrm{pH}$ of the solution $(\Delta \mathrm{pH})$ was plotted against the initial $\mathrm{pH}$ and PZC was then measured. The digital $\mathrm{pH}$ meter (Eutech Instrument, Model $\mathrm{pH} 510$ ) was used to measure the $\mathrm{pH}$ of the solution.

\section{Results and discussion}

\subsection{Synthesis of OPEFB based activated carbon and adsorption capacity test}

Prepared OPEFB was treated with two different concentrations of phosphoric acid and carbonized under nitrogen atmosphere at two different temperatures for 30 min and $1 \mathrm{~h}$, and values of percentage of yield are shown in Table 3. Adsorption capacity experiments were carried out at ambient temperature $\left(28 \pm 2^{\circ} \mathrm{C}\right)$ by using 10 $\mathrm{g} / \mathrm{L}$ of activated carbon from RUN AC1 to AC9, 20 $\mathrm{mg} / \mathrm{L}$ of methylene blue dye solution, at different contact time $(0.25-24 \mathrm{~h})$. The removal of methylene blue and adsorption capacity values were plotted against contact 
times (graphs are not shown), and values of adsorption capacity at equilibrium are also shown in Table 3.

The results from Table 3 showed that \%yield of activated carbon production decreased with an increase of calcination temperature and calcination time at both phosphoric acid concentrations. The reason can be explained on the fact that structure of OPEFB was more decomposed and released as volatile matter at higher temperature and longer calcination time. As a result, \% yield of activated carbon was decreased. However, acid concentration showed a little effect on \%yield of activation carbon (AC1 and $\mathrm{AC} 3, \mathrm{AC} 5$ and $\mathrm{AC} 7$ ).

Table 3 also presents the values of equilibrium adsorption capacity, and it was observed that as the temperature and phosphoric acid concentration are increased, the equilibrium adsorption capacity increased. This can be attributed to greater surface area and bigger pore size of activated carbon when carbonized at higher temperature and acid concentration. However, the carbonization time showed little effect on equilibrium adsorption capacity.

Table 3 Percentage of yield and adsorption capacity of OPEFB based activated carbon

\begin{tabular}{|c|c|c|c|c|c|c|}
\hline \multirow{2}{*}{ RUN } & \multicolumn{2}{|c|}{ \% Yield } & \multicolumn{2}{c|}{$\begin{array}{c}\text { Adsorption Capacity } \\
\text { at equilibrium } \\
\text { (mg/g) }\end{array}$} & $\begin{array}{c}\text { MB } \\
\text { No. } \\
(\mathrm{mg} / \mathrm{g})\end{array}$ & $\begin{array}{c}\text { Iodine } \\
\text { No. } \\
(\mathrm{mg} / \mathrm{g})\end{array}$ \\
\cline { 2 - 5 } Experiment & model & experiment & model & & \\
\hline AC2 & 24.13 & 24.09 & 1.12 & 1.18 & 9.58 & 337.51 \\
\hline AC3 & 18.87 & 18.94 & 1.23 & 1.16 & 10.46 & 341.50 \\
\hline AC4 & 18.77 & 18.68 & 1.54 & 1.60 & 11.42 & 352.47 \\
\hline AC5 & 14.43 & 14.34 & 1.75 & 1.74 & 13.53 & 374.40 \\
\hline AC6 & 13.23 & 13.24 & 1.71 & 1.72 & 12.65 & 371.41 \\
\hline AC7 & 14.02 & 14.09 & 1.82 & 1.82 & 14.49 & 379.38 \\
\hline AC8 & 13.03 & 12.98 & 1.80 & 1.80 & 13.93 & 378.39 \\
\hline AC9 & 17.40 & 17.52 & 1.72 & 1.58 & 14.28 & 375.40 \\
\hline Com. & - & - & - & - & 6.67 & 778.73 \\
\hline
\end{tabular}

Analysis of variance (using Minitab program) was carried out on the basis of the experimental data in order to investigate key variables affecting on \% yield and adsorption capacity $(\mathrm{mg} / \mathrm{g})$ of activated carbon, and the statistical analyses are shown in Fig. 1. It can be seen from Fig. 1(a) that the variables that influence with respect to decreasing the value of $\%$ yield followed the following order: Temp. $>$ Temp. \& Time $>$ Temp. \& Acid $>$ Time. Whist, in Fig. 1(b), the key variables that influence to lower the performance of activated carbon to remove dye are followed the following order: Temp. $>$ Acid $>$ Temp. \& Acid $>$ Time. Based on these analysis of variance data and linear regression analysis ( $p$-value $<$ 0.05 and R-sq > 95\%), fitted polynomial models can be generated and are expressed in the following equations:

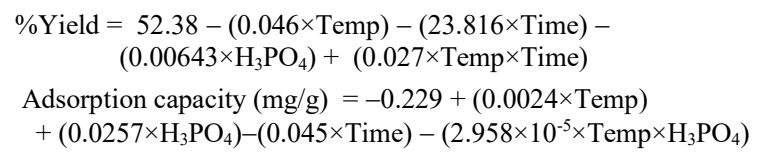

The models were used to predict \%yield and adsorption capacity and the calculated values were shown in Table 3. From Table 3 similar values between the experiment data and those calculated by the regression model were noticed, indicating that the model can be used to predict yield and adsorption capacity at different condition. It was found that among the conditions used, RUN AC3 gave the best quality activated carbon with higher yield and acceptable adsorption capacity as shown in Table 3 and thus was chosen for subsequent Methylene blue adsorption studies.
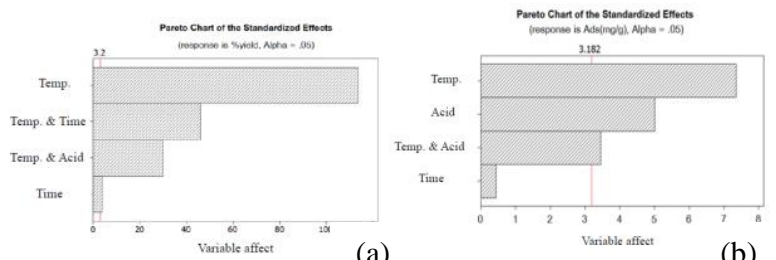

(b)

Figure 1 Analysis of variance effects on (a) \%yield and (b) absorption capacity of activated carbon using Minitab program

\subsection{Methylene blue number and lodine number}

Standard testing method JIS K 1470-1991 and ASTM D4607 were used to determine Methylene Blue Number and Iodine Number of the activated carbon produced and with one selected commercial AC, values are shown in Table 2. The maximum MB No. and Iodine No. were found at RUN AC7 with equals to 14.49 and 379.39 $\mathrm{mg} / \mathrm{g}$, while for RUN AC3 values of 13.62 and 356.46 $\mathrm{mg} / \mathrm{g}$ were observed, which are comparable to the results of commercial activated carbon; i.e. 6.96 and $778.7 \mathrm{mg} / \mathrm{g}$. These results indicated that activated carbon produced in this study contained majoring mesopores while micropores were present in commercial one.

\subsection{Methylene blue (MB) adsorption study}

\subsubsection{Effect of initial MB concentration}

Effect of $\mathrm{pH}$ on $\mathrm{MB}$ removal was examined by varying the $\mathrm{pH}$ of the solution from 2 to 12 , with initial $\mathrm{MB}$ concentration of $100 \mathrm{mg} / \mathrm{L}$, OPEFB activated carbon dosage of $0.5 \mathrm{~g} / 50 \mathrm{~mL}$ at $28 \pm 2^{\circ} \mathrm{C}$ and $4 \mathrm{~h}$ of contact time (reached equilibrium). Adsorption Capacity of activated carbon for $\mathrm{MB}$ at different $\mathrm{pH}$ was shown in Fig 2. It was shown from Fig 2(a) that with an increasing $\mathrm{pH}$ from 2 to 12, the adsorption capacity of activated carbon increased (increased from $3.29 \mathrm{mg} / \mathrm{g}$ to $9.95 \mathrm{mg} / \mathrm{g}$ ). The reason for this is mainly associated with abundance $\mathrm{OH}$ ions at higher $\mathrm{pH}$ facilitated the electrostatic attractions between the positively charged dye cations and negatively charged adsorption site, thus increased the dye uptake. The similar phenomenon has been reported in other studies $[4,5]$. The points of zero charges (PZC) of the activated carbons were also determined and the results were shown in Fig 2(b). PZC was found at $\mathrm{pH}$ 5.65 , indicated that above this $\mathrm{pH}$ of solution adsorption sites of AC produced become more negative and 
enhancing the capacity to adsorb MB positive ions, and confirmed the $\mathrm{pH}$ effect results mentioned earlier.

\subsubsection{Effect of initial MB concentration}

The initial concentration of dye solution provides an important driving force to overcome mass transfer limitation between liquid and solid phases. Initial MB concentration was varied from 20-100 $\mathrm{mg} / \mathrm{l}$ to investigate its effect to adsorption capacity. Fig. 3 showed the absorption capacity of activated carbon at each value of initial MB concentration, and it appeared that the capacity of activated carbon produced increased when initial concentration was increased and the maximum value was noticed at $250 \mathrm{mg} / \mathrm{L}$. However, a further increase in concentration from $150 \mathrm{mg} / \mathrm{L}$ to 250 $\mathrm{mg} / \mathrm{L}$ slightly enhanced the adsorption capacity. With increase in MB concentration, competition for the active adsorption sites increased and slow down the adsorption process.

\subsubsection{Effect of activated carbon dosage}

Adsorbent dosage is another important factor for $\mathrm{MB}$ removal by adsorption process. The activated carbon dose (varying from 0.1 to $1.0 \mathrm{~g} / 50 \mathrm{~mL}$ of $\mathrm{MB}$ solution) on the capacity of activated carbon to remove $\mathrm{MB}$ was shown in Fig. 4. It was observed that MB removal increased with increasing absorbent dose up to 0.5 $\mathrm{g} / 50 \mathrm{~mL}$ of solution and then rate of increase slow down. Initially, the capacity of activated carbon to adsorb MB increased rapidly can be attributed to greater surface area and availability of more adsorption sites. However after the certain dose, although there is abundant of adsorption sites available but there is a shortage of $\mathrm{MB}$ adsorbate in the solution.

(a)

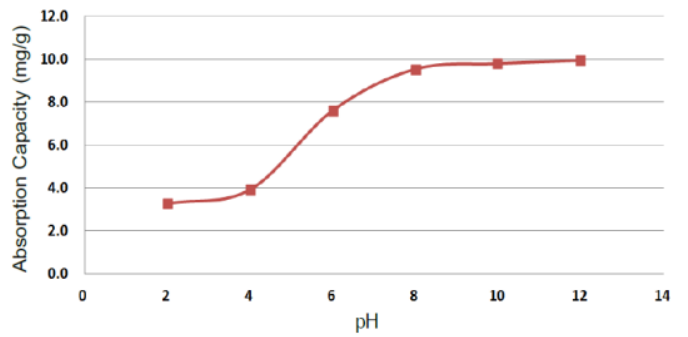

(b)

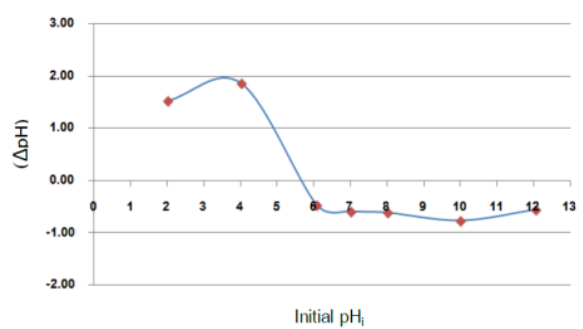

Fig. 2. (a) Effect of $\mathrm{pH}$ solution on $\mathrm{MB}$ adsorption (AC3: $0.5 \mathrm{~g}$ dosage $/ 50 \mathrm{~mL}$ of $100 \mathrm{mg} / \mathrm{L} \mathrm{MB}$ solution, $4 \mathrm{~h}$ contact time)

(b) The point of zero charge (PZC) experiment

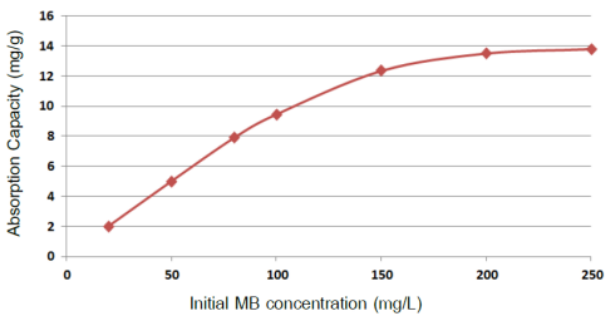

Fig. 3. Effect of initial MB initial concentration on adsorption capacity of activated carbon (AC3: $0.5 \mathrm{~g}$ dosage $/ 50 \mathrm{~mL}$ solution, $\mathrm{pH}=7,4 \mathrm{~h}$ contact time)

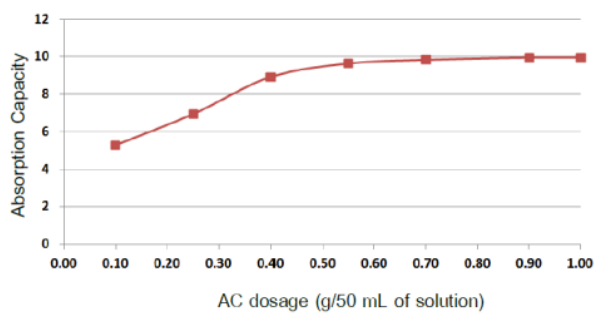

Fig. 4. Effect of activated carbon dosage on adsorption capacity (AC3: $100 \mathrm{mg} / \mathrm{L}$ of MB solution, $\mathrm{pH}=7,4 \mathrm{~h}$ contact time)

\subsection{Adsorption isotherms}

Langmuir and Freundlich models were used to examine the adsorption behavior of activated carbon derived from OPEFB and one commercial AC used in this study, and the linear equations for each model are presented by Eqs. (4)-(5), respectively.

$$
\begin{gathered}
1 / q_{e}=\left(1 / q_{m} b C_{e}\right)+1 / q_{m} \\
\ln q_{e}=\ln K_{F}+(1 / n) \ln C_{e}
\end{gathered}
$$

where $\mathrm{q}_{\mathrm{e}}(\mathrm{mg} / \mathrm{g})$ is equilibrium adsorption capacity, $\mathrm{C}_{\mathrm{e}}$ $(\mathrm{mg} / \mathrm{L})$ is the equilibrium $\mathrm{MB}$ concentration, $\mathrm{q}_{\mathrm{m}}(\mathrm{mg} / \mathrm{g})$ and $\mathrm{b}(\mathrm{L} / \mathrm{mg})$ are Langmuir constants related to adsorption capacity and rate of adsorption, $\mathrm{K}_{\mathrm{F}}$ and $\mathrm{n}$ are Freundlich constants related to a measure of adsorption intensity. The parameters evaluated from isotherm models are reported in Table 4.

Table 4 Adsorption isotherm parameters

\begin{tabular}{ccccccc}
\hline & \multicolumn{2}{c}{ Langmuir Isotherm model } & \multicolumn{3}{c}{ Freundlich Isotherm model } \\
\cline { 2 - 7 } & $\begin{array}{c}\mathrm{q}_{\mathrm{m}} \\
\left(\mathrm{mg} \mathrm{g}^{-1}\right)\end{array}$ & $\begin{array}{c}\mathrm{b} \\
\left(\mathrm{L} \mathrm{mg}^{-1}\right)\end{array}$ & $\mathrm{R}^{2}$ & $\begin{array}{c}\mathrm{K}_{\mathrm{F}} \\
\left(\mathrm{mg} \mathrm{L}^{-1}\right)\end{array}$ & $1 / \mathrm{n}$ & $\mathrm{R}^{2}$ \\
\hline $\mathrm{AC} 3$ & 12.59 & 1.53 & 0.8323 & 7.75 & 0.13 & 0.995 \\
$\mathrm{Com}$ & 7.07 & 0.726 & 0.999 & 4.48 & 0.103 & 0.928 \\
\hline
\end{tabular}

From the correction coefficient showed in Table 3 the adsorption data of AC3 were better fitted in the Freundlich Isotherm model $\left(\mathrm{R}^{2}=0.995\right)$, while for commercial AC were better fitted with the Langmuir Isotherm model $\left(\mathrm{R}^{2}=0.999\right)$. This correction data suggested that a multilayer adsorption of MB occurred on the surface of our activated carbon produced, while a homogenous monolayer adsorption of dye molecules occurred at the outer surface of commercial AC. This may be due to the fact that the experimental AC has contained majority mesopores, resulting in a heterogonous absorption. 


\subsection{BET surface analysis}

BET surface analyzer was used to measure surface area and average pore size of raw OPEFB, OPEFB based activated carbon, and commercial activated carbon and the data were reported in Table 5.

It is shown in Table 4 that the activation by chemical and thermal treatment can improve both surface area and average pore size of raw OPEFB. BET surface area increased from $26.88 \mathrm{~m}^{2} / \mathrm{g}$ to $362.50-381.50 \mathrm{~m}^{2} / \mathrm{g}$ and pore size increased from $2.28 \mathrm{~nm}$ to $2.94-3.18 \mathrm{~nm}$, for raw OPEFB and $\mathrm{AC}$ produced form OPEFB, respectively. Table 4 also shows that for commercial $\mathrm{AC}$, its surface area was greater but had a smaller average pore size when compared to the AC3 and AC7. This may be the reason that can explain the monolayer adsorption behavior of the commercial AC. Due to the fact that commercial $\mathrm{AC}$ has smaller pore size than $\mathrm{AC}$ derived from OPEFB and based on its low MB No. and high Iodine No., it can be concluded that commercial AC used in this study was inferior for $\mathrm{MB}$ adsorption when compared to the OPEFB based AC. SEM images shown on Fig. 5 also confirmed porosity of AC produced from OPEFB.

Table 5. BET surface analysis

\begin{tabular}{lcc}
\hline \multicolumn{1}{c}{ Sample } & $\begin{array}{c}\text { BET surface area } \\
\left(\mathrm{m}^{2} / \mathrm{g}\right)\end{array}$ & $\begin{array}{c}\text { Average pore sizt } \\
(\mathrm{nm})\end{array}$ \\
\hline Raw OPEFB & 26.88 & 2.28 \\
AC3 & 362.50 & 2.94 \\
AC7 & 381.50 & 3.18 \\
Commercial AC & 814.30 & 2.38 \\
\hline
\end{tabular}
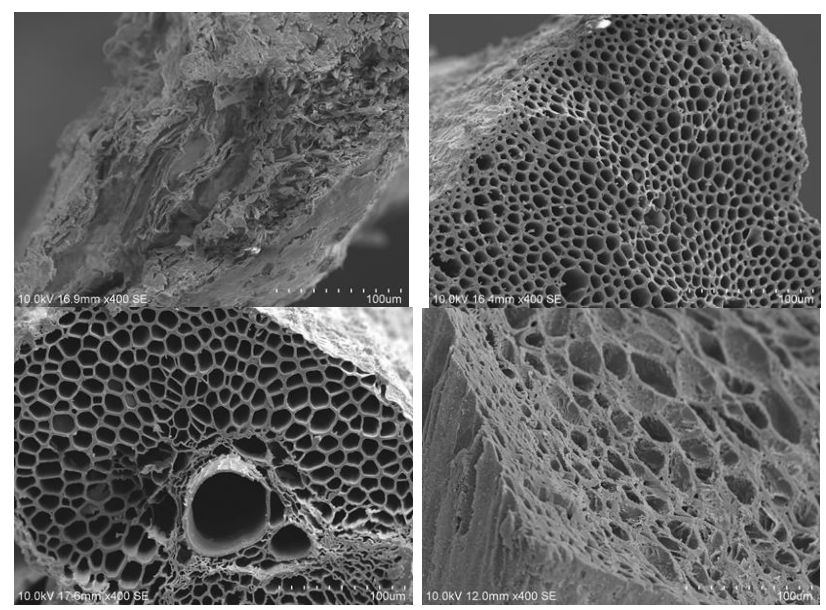

Fig. 5. Porosity images observed by SEM of raw OPEFB (upper left), AC3 (upper right), AC7 (lower left), and commercial AC (lower right)

\section{Conclusion}

The activated carbon produced from oil palm empty fruit bunch (OPEFB) show a good adsorption capacity of Methylene blue dye. The activated carbon yield obtained ranged from $13.03-23.81 \%$ and equilibrium adsorption capacity was observed from $1.12-1.82 \mathrm{mg} / \mathrm{g}$. It was found that the best condition for producing activated carbon was obtained when using $60 \% \mathrm{H}_{3} \mathrm{PO}_{4}$ as an activating agent and carbonized at $500^{\circ} \mathrm{C}$ for 30 minute. Carbonization temperature was the most significant effect on both the yield and adsorption capacity of AC compared to acid concentration and carbonization time. The produced activated carbon had a surface area of $362.5 \mathrm{~m}^{2} / \mathrm{g}$ and average pore size of $2.94 \mathrm{~nm}$. Methylene blue and Iodine numbers were 13.62 and $356.46 \mathrm{mg} / \mathrm{g}$, respectively. The optimum condition for the adsorption of MB from aqueous solution by produced activated

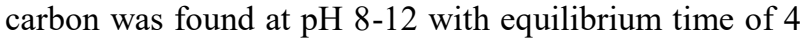
hours. Results demonstrated that the equilibrium data was well fitted by Freundlich isotherm model with the isotherm constants $\mathrm{K}_{\mathrm{F}}$ of $7.75 \mathrm{mg} / \mathrm{g}$ and $1 / \mathrm{n}$ of 0.13 .

However, adsorption capacity of the experiment AC for $\mathrm{MB}$ adsorption was lower than the values from some researches, thus future research such as surface modification needs to be carried out.

\section{References}

[1] Alam M.Z., et al. The Factors Affecting the Performance of Activated Carbon Prepared from Oil Palm Empty Fruit Bunches for Adsorption of Phenol, Chemical Engineering Journal, 155, 2009, 191-198.

[2] Alam M.Z., et al. Statistical Optimization Of Adsorption Processes For Removal Of 2,4 Dicholophenol By Activated Carbon Derived From Oil Palm Empty Fruit Bunches, J. of Environmental Science, 19, 2007, 674-677

[3] Ooi C.H, et al. Conversion and Characterization of Activated Carbon fiber derived from Oil Palm Empty Fruit Bunch Waste and its Kinetic Study on Urea Adsortion, J. of Environmental Management, 197, 2017, 199-205.

[4] Foo K.Y., and Hameed B. H. Preparation of Oil Palm (Elaeis) Empty Fruit Bunch Activated Carbon by Microwave-assisted $\mathrm{KOH}$ Activation for The Adsorption of Methylene Blue, Desalination, 275, 2011, 302-305.

[5] Sajab M. S, et al. Cationic and Anionic Modification of Oil Palm Empty Fruit Bunch Fibers for the removal of dyes from aqueous solutions, Bioresource Technology, 128, 2013, 571-577. 